\title{
Towards closure at Jabiluka: rehabilitation of the Boyweg-Almudj sacred site complex
}

\author{
H.D. Smith APChem Scientific Consultants, Australia
}

A. Thompson Northern Land Council, Australia

\begin{abstract}
Jabiluka is an underground uranium deposit of significant economic potential located within the contiguous cultural and natural environments in Australia known as Kakadu National Park. Following a period of public controversy in the late 1990s, the development of the mine was shelved and the site was placed into care and maintenance without any ore being processed. Traversing Jabiluka is a significant complex of sacred Aboriginal sites known as Boyweg-Almudj, which was where pre-mining drilling activities were undertaken in the 1970s.

This paper considers the damage that has been done to Boyweg-Almudj from the traditional Aboriginal owners' perspective and the steps that have been taken since 2010 to have this area rehabilitated. The outcomes are discussed not only in respect of environmental benefit, engagement and cultural acceptance but also in terms of the application of traditional Aboriginal knowledge to the remediation and cultural reclamation of the Jabiluka site. These actions constitute part of an evolving model for integrating Aboriginal and non-Aboriginal knowledge into the closure of mine sites across Australia's Northern Territory that has been in development since 2006.
\end{abstract}

\section{Introduction}

Mirarr are the traditional Aboriginal owners of the lands in and around Jabiluka, an underground uranium deposit of significant economic potential located within the contiguous cultural and natural environments in Australia known as Kakadu National Park, and they retain a responsibility to ensure that future generations can continue to manage the post-rehabilitation environment at Jabiluka according to their cultural mores. Mirarr influence extends south, beyond the Ranger uranium mine (which is now progressing towards closure) and towards Koongarra, an exploration lease, which has recently been surrendered and is in the process of being integrated into the World Heritage-listed Kakadu National Park.

Surface and groundwater from Jabiluka connect to the Ramsar-listed Magela wetlands and the BoiwegBagaloy soak to the west. Both water bodies are of spiritual and cultural significance to Mirarr and have specific and detailed cultural values that are especially related to groundwater. These values are discussed in more detail in Section 4.1.

Exploration for uranium began at Jabiluka in 1969, and two ore bodies were identified in 1971 and 1973 (McKay and Meiitis, 2001). Energy Resources of Australia (ERA) finally began development of the underground mine in 1998, following a hiatus extending from 1983 to 1996 when new uranium mines were banned under Australian government policy. Construction commenced with the excavation of an inclined access tunnel (the 'decline'), but mine development activity was beset by political and public relations problems and strong community opposition. The Jabiluka project was finally shut down by 2000 without any ore being processed. Following another change in ERA's ownership in 2001, the fate of Jabiluka was renegotiated and the property was put into 'long-term care and maintenance'. In mid-2005, the decline was backfilled, and revegetation of disturbed surface areas was undertaken. The development of Jabiluka, from the Mirarr perspective, was effectively consigned to history. 
A key point of contention in the dispute between the Australian government, ERA and the Mirarr in the late 1990s regarding the mining of the deposit related to the conflicting claims regarding the size of the Boyweg-Almudj complex and its cultural and spiritual significance. Nonetheless, construction of the mine was allowed to proceed based on the original mineral lease having been granted (1982), the transfer of ownership rights (1991), the government's suspension of its 'no new mines' policy (1996) and despite the absence of a cultural heritage management plan (Commonwealth of Australia, 1999). Following lengthy public protests, mining was curtailed in 1999, and the project remains on hold. Development of the deposit will now only proceed under the terms of the more recent 'care and maintenance' agreement, under which the consent of the Mirarr traditional owners is required to mine, which to this day has not been given. The contentiousness surrounding the development of Jabiluka soured the relationship between ERA and the traditional owners, which despite the 'care and maintenance' agreement and ensuing efforts to set things right (such as the project described in this paper) remains fragile and at times tense.

More recently, steps have been taken to rehabilitate Jabiluka and place it in a position where it too could be incorporated into Kakadu National Park. A series of small projects aimed at generating greater trust between ERA and Mirarr have been instigated (Smith, 2012a; Jacobsen, 2012). These projects involve the integration of traditional cultural and ecological knowledge with engineering principles to reach a standard of rehabilitation that is mutually acceptable to ERA and Mirarr (Smith, 2008, 2009). One of these projects involved the removal of drill hole infrastructure remaining from the exploration phase at Jabiluka and the installation of four groundwater monitoring bores, which are necessary to assess the level of impacts on the physical quality and cultural values of Boyweg groundwater. The boreholes would themselves be removed after a maximum of five years of operation.

The main drivers for this particular project were:

- A request from Mirarr to have Boyweg-Almudj (also referred to as Mine Valley) returned to a pristine state and one that befits the wider cultural landscape of Kakadu National Park.

- A recommendation made by Ministers Parer and Hill during the review of the Jabiluka Environmental Impact Statement in 1999 to demonstrate that there would be no impacts on groundwater.

- A desire amongst Mirarr to understand the impact that mining-related disturbances of the $1990 \mathrm{~s}$ might have had on groundwater that runs westward to the Boyweg waterhole (and, by implication, the impacts on its cultural values).

This paper briefly reviews progress that has been made in the effort to address these issues and to repair some of the negative aspects of relationships between Mirarr and other stakeholders. These will be at least partly addressed once rehabilitation and 'closeout' of the Boyweg-Almudj complex has been completed.

\section{$2 \quad$ Method}

Documents describing the geology and hydrogeology of Mine Valley and copies of original maps showing locations of exploration drill sites were sourced. Four excursions were undertaken with a senior male traditional owner into Mine Valley in 2006 and 2007 to identify, record and assess the state of drill holes and other residual infrastructure. Locations were recorded using two hand-held GPS instruments, and a full photographic record was made.

Discussions were then held with Mirarr to determine the extent of rehabilitation works that should be undertaken. A plan of rehabilitation was prepared and submitted to ERA, who then undertook the necessary risk assessments and sought appropriate government approvals.

In 2009, ERA completed additional surveys using more accurate Trimble surveying equipment, original exploration survey logs and the data points generated during the 2006 and 2007 excursions. Once identified, old bores were excavated to a depth of $450-600 \mathrm{~mm}$ and the casing was cut using an air- 
operated saw to reduce the risk of fire. Cut-down bores were plugged and capped with concrete before the sites were backfilled and contoured (Hubbard and Dobson, 2010).

In addition, a range of other residual infrastructure was removed by hand (e.g., star pickets and pipes) and a 3.5 tonne excavator was used where necessary (e.g., for concrete slabs and tie down blocks). Weed spraying was undertaken as required, and sumps and tracks were backfilled and rehabilitated.

\section{$3 \quad$ Results}

The extent of Mine Valley and the location of exploration boreholes are shown in Figure 1. Desktop studies identified over 250 exploration holes, many of which were located on the Magela floodplain, close to the Boyweg-Bagaloy soak. The 2006 and 2007 surveys failed to locate physical remains of any of these bores (other than a few star pickets) and concluded that they had been effectively obliterated by 30 years of seasonal changes in an area that is subject to frequent inundation.

Surveys undertaken in 2006 and 2007 identified 116 sites, which included 77 of the 250 boreholes and numerous star pickets, concrete slabs, sumps and approximately $500 \mathrm{~m}$ of steel pipe. The 2009 survey identified a further 14 boreholes. The bores ranged in dimension and were constructed from steel or PVC. The majority of them were dry and protruding from the ground; to provide context, two of them are shown in Figures 2 and 3.

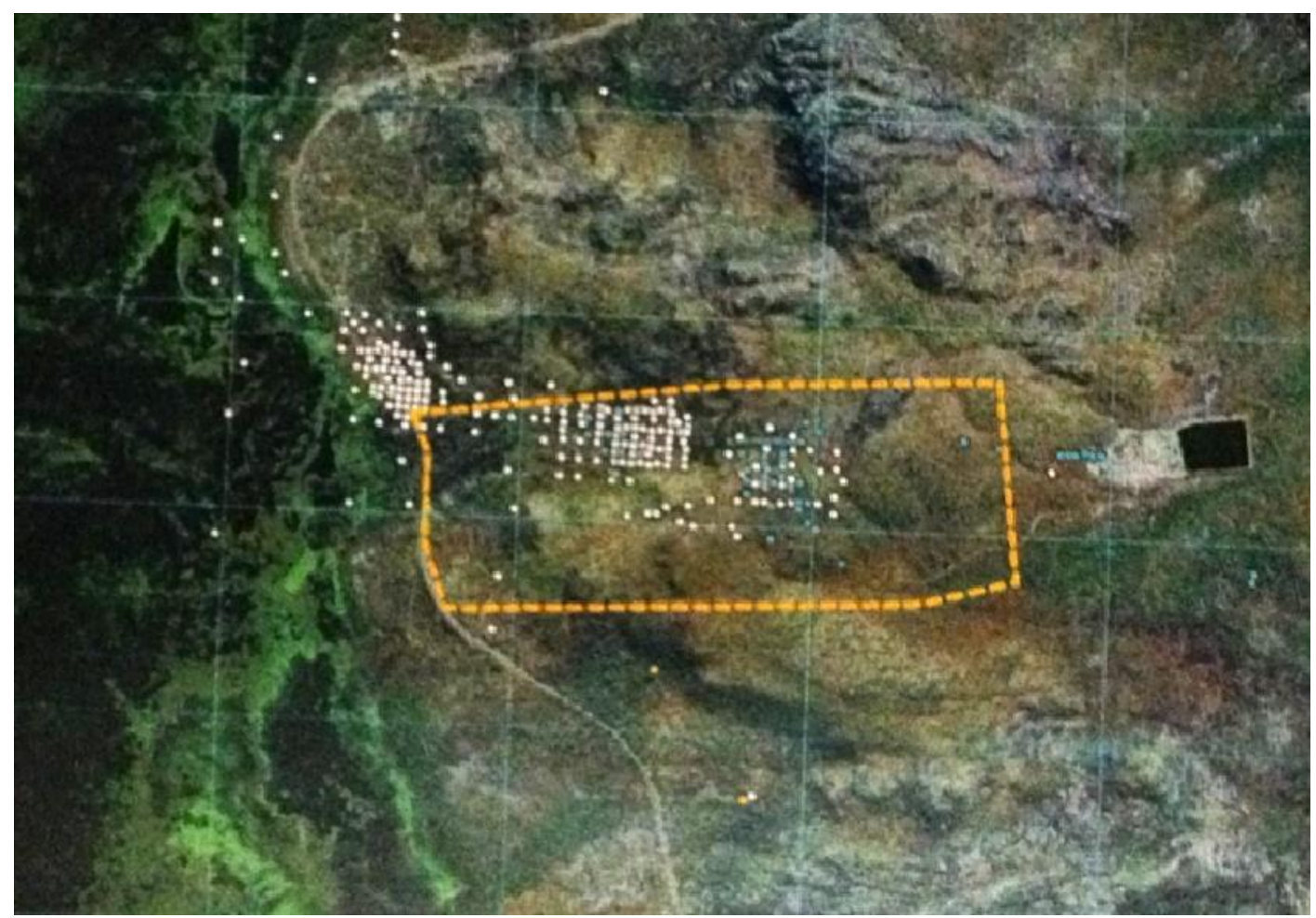

Figure 1 Map showing locations of Mine Valley (contained within the dashed line) and exploration bores dating back to 1974 


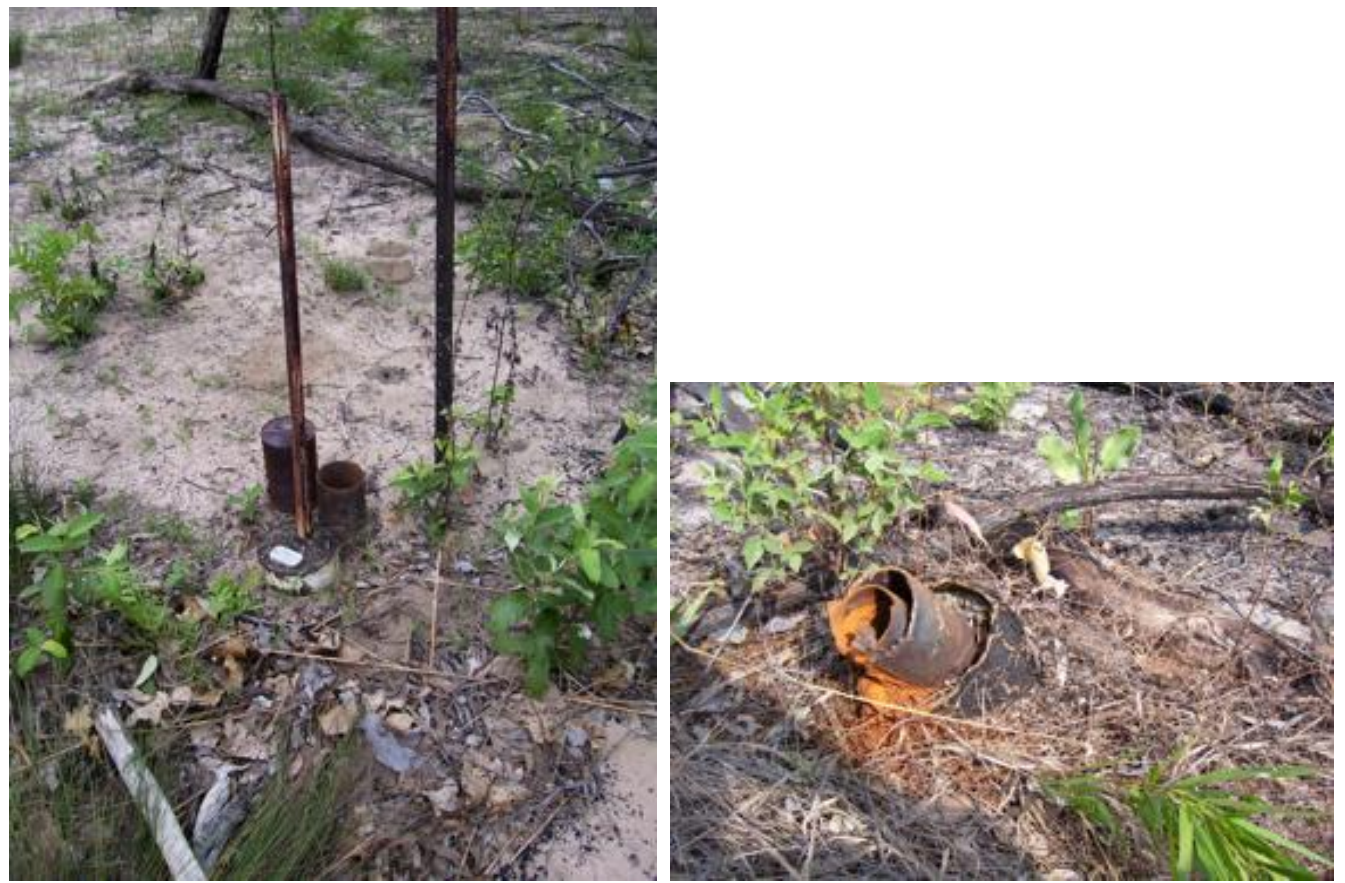

\section{Figure 2 (left) Unlabelled borehole with associated datum point and star pickets, (right) Borehole DH 242}

As a result of work undertaken in 2009, a total of 91 boreholes were rehabilitated, and several tonnes of residual concrete, PVC plastic and metal were removed from Mine Valley. Unfortunately, errors in the mapping process during the approvals phase meant that a number of boreholes that were just within the boundaries of Mine Valley were not rehabilitated. This work is scheduled for final completion in 2013.

\section{$4 \quad$ Discussion}

Since the original decision to approve the development of uranium mines on Mirarr land in the late 1970s and early 1980s, relationships between the mining companies holding the Ranger and Jabiluka leases and the Mirarr have been strained. Rehabilitation of the Boyweg-Almudj complex represents one of three small projects (Smith, 2012a; Jacobsen, 2012) that aim to improve engagement and develop stronger working relationships between ERA, the current owners of the Jabiluka mine (and also the owner/operator of Ranger) and Mirarr. Additionally, these three projects will serve to prepare the Jabiluka site for integration into Kakadu National Park in much the same manner as has recently happened with the nearby Koongarra deposit. It is also hoped that successful completion of the three projects will engender greater involvement of Mirarr during closure of the Ranger mine - a process that will require application of their traditional knowledge if satisfactory outcomes to the Mirarr are to be achieved.

A number of difficult relationship issues plagued this modest rehabilitation and water monitoring project, and Mirarr were unhappy with the delays caused by a number of factors. ERA was perceived to be slow in passing rehabilitation plans through its management, and this was followed by difficulties in the contracting and procurement stages. The government's slow issue of the certificates required to undertake work on a sacred site (even at the request of the site's traditional owners) caused further delays, and there was some confusion over the status of application forms required to undertake groundwater sampling and remove the boreholes that were inadvertently excluded from the original work plan. Despite these setbacks delaying and slowing down progress on the project by three to four years, physical rehabilitation at Boyweg-Almudj is now largely complete. 


\subsection{Cultural importance of Boyweg - Almudj}

Successful rehabilitation of Mine Valley was a significant forward step because Boyweg-Almudj is a complex of sites covering the valley that Mirarr consider an integral part of the cultural landscape. 'Boyweg' is a discrete swamp on the edge of the Magela wetlands, while 'Almudj' is a rocky outcrop to the southeast of the Jabiluka escarpment. Mirarr state that the complex comprises:

- The Boyweg-Bagaloy soak.

- The Almudj rock art site.

- The dreaming track that connects the two places.

- Other places along this track that are associated with other ancestral beings.

Mirarr believe the complex is a place where the Rainbow Serpent (Almudj) morphed into the form of a knob-tailed gecko (Boyweg), travelled across the valley and sank down into the Bagaloy soak. The site is said to never dry out because Almudj remains below the ground there. It is part of the Mirarr creation story - a part that gave to them their laws, ways of life and social structure. The Boyweg-Almudj site is considered djang andjamun (dangerous and restricted), with surface and subsurface manifestations that are linked to the presence of groundwater. It is classified as a men's site, and women are not allowed to go there. Damage to this complex impacts on Mirarr cultural identity and practice, while failure to rectify that damage will promulgate those impacts well into the future.

Being djang andjamun meant that a number of culturally sensitive issues had to be considered during rehabilitation of the complex. The environmental impacts caused by the residual infrastructure were undoubtedly of low significance, but the cultural impacts were of great concern. Mirarr felt responsible for the safety of workers and worried about the implications of further damaging the surface and subsurface on the creation spirits. Mirarr did not wish further disturbance to occur, as this might induce an adverse response from Boyweg and Almudj, but ultimately they had to balance this against the need for healing of the land and maintenance of groundwater systems.

To meet cultural requirements and allay concerns, heavy machinery was excluded from the Boyweg-Almudj complex, meaning that boreholes were cut and removed and that sites were refilled either by hand or use of a small loader. Fortunately, most of the larger infrastructure remnants (including concrete slabs and tiedowns) were located close to the main road and at the edge (or periphery) of the more sensitive areas of the site, allowing the materials to be successfully removed.

\subsection{Groundwater}

Following removal of residual surface and subsurface infrastructure and scrap, attention turned to determining the extent of impact of pre-mining activities on water quality at the Boyweg-Bagaloy soak. In the Aboriginal belief system, the health and well-being of creation spirits like Almudj depend upon vitality of groundwater (Smith, 2012b). If they are forced to depart as a result of increased contamination, then the soak would dry out, renewal of the groundwater systems would not occur and future generations of Mirarr would suffer.

Modelling studies suggest that there is a slow movement of groundwater down gradient from the Jabiluka ore-body towards the soak, but they also suggest that any upgradient disturbance would have only minimal impact (Kalf and Dudgeon, 1999). This could never be proved because development was curtailed. To Mirarr, however, the ore-body and therefore Boyweg and Almudj had been disturbed, so there remained a possibility that groundwater impacts would still be seen at Bagaloy soak. The 2006 and 2007 borehole surveys failed to identify any pre-existing boreholes suitable for ongoing groundwater monitoring, so new ones had to be constructed if impacts were to be assessed.

Identification of four sites suitable for groundwater monitoring bores proved difficult. Permission to install three monitoring bores in close proximity to the soak was not forthcoming, while permission to site the 
fourth bore along the dreaming trail in Mine Valley was hard-won. Ultimately, the need to demonstrate the extent of impact that construction of the underground decline has had on the quality and cultural values of groundwater at the Boyweg soak was deemed essential and more important than the amount of disturbance that would be caused during construction of new groundwater bores. These bores were constructed during 2009, but further delays in respect of the issue of permits to collect groundwater samples means that consistent monitoring has yet to be undertaken.

Available baseline water chemistry data related to the rehabilitated boreholes are limited to 48 bores and restricted to the years between 1975 and 1981 (Kilborn, 1976; Deutcher et al., 1980; PanContinental Mining Ltd, 1981) and between 1992 and 1996 (Kinhill Engineers, 1998). Data consist mainly of records of $\mathrm{pH}$, electrical conductivity, total dissolved solids, hardness and sporadic measures of ions $\left(\mathrm{HCO}_{3}, \mathrm{CO}_{3}, \mathrm{Cl}, \mathrm{F}\right.$, $\mathrm{SO}_{4}, \mathrm{PO}_{4}, \mathrm{NO}_{2}, \mathrm{NO}_{3}$ and $\mathrm{NH}_{4}$ ) and metals/metalloids ( $\mathrm{Na}, \mathrm{K}, \mathrm{Ba}, \mathrm{Ca}, \mathrm{Mg}, \mathrm{Si}, \mathrm{Mn}, \mathrm{Al}, \mathrm{Fe}, \mathrm{Cu}, \mathrm{Pb}, \mathrm{Zn}, \mathrm{Cd}, \mathrm{Hg}, \mathrm{As}$, $\mathrm{Ni}$ and $\mathrm{U})$. None of the data collected over this 21 year period were directly measured at the BoiwegBagaloy soak.

Monitoring of the new bores commenced in 2012, and to date only a limited amount of data is available. This was collected when the bores were constructed and is generally consistent with that obtained during exploration, but the small volume of data makes it impossible to draw statistically valid conclusions at this time.

\subsection{Indicators of success}

Rehabilitation of Boyweg-Almudj was undertaken mainly to satisfy cultural requirements, making successful measurement of the project's outcomes difficult to define in scientifically objective terms. The site is one that is generally avoided, so there would be little point in assessing levels of future visitation or other interaction with the site and using that as an indicator. The types of ceremony that might be performed at or near the site and their timing were not deemed pertinent to the project in the 1990s and were not recorded. Consequently, a baseline against which frequency of visitation could be measured does not exist. The only practical indicators of success lay in the fact that residual infrastructure and scrap has been removed and that Mirarr are generally appreciative of the outcomes and effort that has been made.

A demonstration that there has been no impact on groundwater quality will also serve to demonstrate that no long-term damage has occurred. Early cessation of development at Jabiluka and modelling of the hydrology of Boyweg-Almudj suggest that impacts of mining on groundwater quality and levels at the Boyweg-Bagaloy soak will be minimal. However, this may take several years to establish, and until a satisfactory amount of monitoring has been undertaken questions will remain. Only when minimal impact is proved can Mirarr be satisfied that there has been no adverse effect on the cultural values they ascribe to water from the soak. And only then can the rehabilitation of Mine Valley be considered a success.

\subsection{Implications for the future}

Although rehabilitation of Boyweg-Almudj is only a small project, it has larger implications for closure of the nearby Ranger uranium mine, where a wider range of traditional knowledge is to be applied. At BoywegAlmudj, little traditional ecological knowledge needed to be applied because there was a stronger focus on culture and Mirarr spiritual beliefs, but also because widespread ecosystem reconstruction was not required. As a result, an improved working relationship with Mirarr appears to have been generated. This is important because without it, successful closure of the Ranger mine, which will rely on an increased level of participation from Mirarr, may not be achieved.

\section{Conclusions}

The Boyweg-Almudj complex is one of the most significant sacred sites for Mirarr. The work undertaken in this rehabilitation project reflects the level of patience and engagement that is required for developing a functional working relationship between Aboriginal people and a mining company where an adverse relationship previously existed. It also highlights the challenges and frustrations posed to successful and 
timely implementation of 'best of intention' agreements between companies and traditional owners by the various bureaucratic procedures and regulations meant to protect such sites but that complicate efforts to ensure a mutually acceptable and successful outcome.

Although this was only a small project, rehabilitation of the Boyweg-Almudj complex provides an important example of applying cultural knowledge and requirements to mine-site rehabilitation processes. Despite some procedural difficulties, remediation of the physical impacts on the surface and subsurface BoywegAlmudj complex have been successfully completed to the general satisfaction of Mirarr. However, it is recognised that more groundwater monitoring is required to ensure that concerns about the cultural and environmental values of water within and emanating from the complex are fully addressed.

A similar approach is to be applied to finalising the remaining two projects that will complete rehabilitation at Jabiluka: removal of remaining infrastructure and recontouring of the hill at the back of Mine Valley and the finalisation of clearing the old Djarr-Djarr campsite. Once these are completed, the cultural values of Jabiluka will be restored and it will be able to fit back into the contiguous cultural and environmental landscape that is Kakadu National Park.

\section{Acknowledgement}

The authors gratefully acknowledge the ongoing support of the Mirarr and the Gundjeih'mi Aboriginal Corporation for this project and their willingness to share their culture and traditional knowledge in the pursuit of developing systems of mine closure excellence.

\section{References}

Commonwealth of Australia (1999) Jabiluka: The Undermining of Process - Inquiry into the Jabiluka Uranium Mine Project, Report of the Senate Environment, Communications, Information Technology and the Arts References Committee, esp. pp. 39-46 and 164-166.

Deutscher, R.L., Mann, A.W. and Giblin, A. (1980) Groundwater geochemistry in the vicinity of the Jabiluka deposits, in Proceedings International Uranium Symposium on the Pine Creek Geosyncline, J. Ferguson and A.B. Goleby (eds), 4-8 June 1979, Sydney, Australia, International Atomic Energy Agency, Vienna.

Hubbard, J. and Dobson, C. (2010) Mine Valley rehabilitation 2009 - closeout report, Energy Resources of Australia, Internal Paper. Jacobsen, N. (2012) Progressive rehabilitation 2012-2017, pilot projects, Energy Resources of Australia Internal Paper.

Kalf, F.R.P. and Dudgeon, C.R. (1999) Analysis of long-term groundwater dispersal of contaminants from proposed Jabiluka Mine tailings repositories, Supervising Scientist Report 143, Environment Australia, Canberra.

Kilborn, M.W.P. (1976) Groundwater investigations for Jabiluka orebody, Report to Pancontinental Mining Ltd.

Kinhill Engineers (1998) The Jabiluka Mill Alternative Public Environmental Report, Kinhill Pty Ltd.

McKay, A.D. and Meiitis, Y. (2001) Australia's uranium resources, geology and development of deposits, AGSO-Geoscience Australia, Mineral Resources Report 1.

Pancontinental Mining Limited (1981) A Review of the Jabiluka Project Environmental Studies, Vol. 2, Chemistry of Groundwaters of the Jabiluka Project Area.

Smith, H.D. (2008) Using traditional ecological knowledge to develop closure criteria in tropical Australia, in Proceedings Third International Seminar on Mine Closure (Mine Closure 2008), A.B. Fourie, M. Tibbett, I. Weiersbye and P. Dye (eds), 14-17 October 2008, Johannesburg, South Africa, Australian Centre for Geomechanics, Perth, pp. 47-56.

Smith, H.D. (2009) Strangers in a foreign land - developing cultural closure criteria for mines in Australia's Northern Territory, in Proceedings Fourth International Seminar on Mine Closure (Mine Closure 2009), A.B. Fourie and M. Tibbett (eds), 9-11 September 2009, Perth, Australia, Australian Centre for Geomechanics, Perth, pp. 3-12.

Smith, H.D. (2012a) Post closure planning for Ranger uranium mine, in Proceedings Seventh International Seminar on Mine Closure (Mine Closure 2012), A.B. Fourie and M. Tibbett (eds), 25-27 September 2012, Brisbane, Australia, Australian Centre for Geomechanics, Perth, pp. 667-674.

Smith, H.D. (2012b) Aboriginal perspectives on mine closure and oil well abandonment, in Proceedings Seventh International Seminar on Mine Closure (Mine Closure 2012), A.B. Fourie and M. Tibbett (eds), 25-27 September 2012, Brisbane, Australia, Australian Centre for Geomechanics, Perth, pp. 641-650. 
